Kohl: a Journal for Body and Gender Research

Vol. 3, No. 1 (Summer 2017)

\title{
On Dream Making and the Aspiring Migration of Queer Bodies
}

\author{
Yara Mamdouh Ahmed
}

\begin{abstract}
:
In looking at the relationship between the body and the state when it is at its most vulnerable, in the sites of imagination and its making, this paper will explore how queer bodies imagine movement in the advent of a neoliberal discourse of rights, laws, and citizenship. What is it in the apparatuses of the neoliberal moment that washes over the processes of dreaming of a "somewhere else," shaping the potentialities of movement, the spaces we can imagine and create, and the spaces that seem unreachable? The notion of citizenship will be a primary focus in my research, particularly sexual citizenship, as an incarnation of the state's capacity to fix the subject to rigid structures and dispositifs of control.
\end{abstract}


A few months ago, I attended a workshop session organized by an LGBT+1 activist group in Egypt on refugee and asylum seeking. The workshop brought together youth, most of whom were Egyptian, from the Meem community in Cairo, who were interested in learning about the procedures of seeking asylum and refugee status, and it aimed to open up a space for the discussion of personal migratory aspirations. Twenty or so participants, predominantly gay, cisgendered men, shared stories about their experiences, opinions on the most "suitable" countries to migrate to, and information on how to prepare for migration to different countries. What struck me most about the discussions was the notion of "suitability," as well as the practices of naming and categorization within the various state structures that provided the capacity for individuals to transition between categories - even if on a strictly imaginary level: from professional migrant to refugee, or from political asylum seeker to emigrant. The workshop also prompted interesting questions about the position of sexuality within the state structure. What kind of aspirations can queer ${ }^{2}$ bodies navigate if their dreams and desires are always framed within the context of the state? How do queer bodies construct ideas of a "better life" in the advent of a neoliberal discourse of rights, laws, and citizenship, where a certain understanding of what is inside and outside, possible and impossible, legal and illegal, real and unreal have come to be established? What is it in the apparatuses of the neoliberal moment that washes over the processes of dream making, shaping the potentialities of movement - the spaces we can imagine and create and the spaces that seem unreachable? Drawing on Foucault's notion of biopolitics, I want to explore whether queer bodies, as biopoliticised subjects of the state, imagine better forms of living through imagining better forms of citizenship; how abundant a space it leaves for new ways of living to be envisioned and practiced?

This paper is limited in scope, as it is not based on extensive fieldwork. I will base my study, however, on scholarly material that tackles sexual citizenship, migration, subjectivity, and Lazzarto's interpretation of the societies of control in order to explore the relationship between the body and the state when it is at its most vulnerable, in the sites of imagination and its making. I will also take an ethnographic approach to draw on the particular workshop space I previously mentioned. Material, whether scholarly or otherwise, that is written by or on queer individuals or groups in Egypt is very limited. My approach then will have more of a theoretical engagement with the questions I pose rather than an engagement with particular cases and

1 LGBT+ is translated to p.p.?.P in Arabic (the acronyms stand for mitliyy, mitliyya, mughayer, and muzduj which in English would be translated to gay, lesbian, transgender, and bisexual). This particular group identifies with this translated vocabulary; however, to say that it connotes the same cultural meaning as LGBT+ is reductive. Language plays a crucial role in carrying meanings that are ascribed to it and by translating the Arabic back into English, the ascribed meanings shift and change. For the purpose of this paper, I will then use the transliterated term Meem to refer to the group of people who have come together in the particular context of the workshop. It is important in that regard to recognize that "concepts are shaped by the contexts in which they emerge." Even though I use "Meem community" to refer to a particular set of experiences in Egypt, it is important to recognize the kind of invisibilities that such language might entail (Richardson, 2017). To a large extent, in non-normative sexuality discourses, the Meem categories present the same challenge as LGBT+ in its reliability on politicized identities, and exclusion is bound to occur.

2 In this paper, I use queer to refer to a process that moves beyond the structured vocabulary of essential identity categories. Queer allows for a fluid and multiple perception of gender and sexuality that steers away from fixed and rigid definitions. In that sense, queer becomes a process of endless becoming that continuously agitates and challenges binaries. 
experiences. I would finally like to point out that the workshop brought together a particular closed circle of young people who are somewhat aware of the language of LGBT+ - whether they choose to identify with it or not - and doesn't necessarily reflect the general positions and subjectivities of queer Egyptians.

\section{Contextualizing the Field}

Since 2001 Egypt's state police have been targeting and arresting men suspected of "homosexual conduct" (Human Rights Watch, 2004). Even though there is technically no law against homosexuality, people who are suspected of same-sex relations are accused of debauchery. Categories like LGBT+ are nonexistent for the state. These bodies, sexualized in state discourse, are lumped under the word shezoz, meaning abnormality or deviance. Labeling practices in this instance is the state's mode of management of undesirable bodies (Agier, 2011). In concealing individual subjectivities, homogenizing them into a group, stripping them bare, and moving them into zones of exception, the state establishes its control over them. Persecution and management of queer bodies provided an opportunity for state apparatuses "to 'perform' a discourse of national security through which national sovereignty was (re)produced and political order was maintained" (Pratt, 2007, p. 129).

Arguments have varied as to the reasons behind the 2001 crackdown on same-sex relations in Egypt. Hossam Bahgat, the founding executive director of the Egyptian Initiative for Personal Rights (EIPR) argued that the crackdown was an attempt to divert the attention of the public from politico-economic crises in Egypt (Bahgat, 2013). Nicola Pratt (2007) takes Bahgat's argument further and explores how "the punishment of homosexuality was not only represented as a means of securing Egyptian manhood but also as a means of protecting Egyptian national security" (p. 137). Heteronormative discourses in Egypt is not only confined to the domestic sphere of the household where it is conducive to ascribing gender roles, but is also essential in maintaining a heterosocial structure that extends to definitions of citizenship and to the blueprints of the nation-state (Pratt, 2007). This process is particularly blatant in a religiopolitical framework where religious narratives have become part and parcel of state legislations and is complicit in the regulation of bodies (Pratt, 2007):

Sexual relations and identities are not only a private/intimate matter but also "an arena of constant surveillance and control" and an inextricable part of the national and state processes that constitute the sphere of international politics (Pratt, 2007, p. 130).

Arrests have also increased noticeably since 2013, marking the military coup on Islamist president Mohamed Morsi. It is posited that the increased crackdown attempts to stretch the regulatory capacity of state apparatuses after the revolution, and to push forth a façade of control, morality, and religiosity. The crackdown on same-sex relations in Egypt mainly targeted gay men and transgender women; 3 this entailed

3 "Transgender women are usually prosecuted as men because the police, courts and news media in Egypt... make no meaningful distinction between gay men and transgender women" (Stack, 2015). 
online surveillance, raids on private homes, torture, and invasive anal examinations. The aim of such purposeful hounding, according to several queer activists, was to gain favor of a dominantly Muslim society by positing the new regime as conservative, while at the same time pushing forth a seemingly more "liberal" stance that was promoting itself as more appealing than the "radical" Muslim Brotherhood regime (Bahgat, 2013; Luongo, 2012). The production of the figure of the "other" demonized "loose secular" sexuality on one hand, and vilified the "radical" Islamist regime on the other, which ensured the status of the new regime as the paternal protector of the nation.

Amidst threats of persecution and stigmatization, it is somewhat clear why some queer bodies, whether directly targeted or not, have opted for migration as a means towards attaining the imagined "better life." Queer activism in Egypt has gained more ground since the revolution. The scene has been mostly underground in terms of campaigning and awareness raising for fear of security threats. While the reasons behind this increased activism and visibility is not a topic to be discussed at length in this paper, it contextualizes my approach in terms of how the networking and the coming together of people in such settings contributes to the constitution of affective subjectivities that shape and restructure the imaginations and aspirations of queer bodies.

\section{The Nation-State and Dispositifs of Management}

It has become increasingly difficult for us to think of the body outside the context of the state, citizenship, its regulations, its identity cards or lack of, and the structures hidden under the guise of civilization and modernity that have been scrambling to weigh, measure, and frame our bodies. Life within the realm of the state has been so normalized that anything that lies outside of it has been rendered bare, less than human (Agamben, 1998). The dispositifs ${ }^{4}$ of governmentality in these contemporary moments extend a sort of othering to bodies and mark them as undesirable, and illegitimate. Processes of expulsion by state apparatuses have articulated themselves more and more in recent years and zones of exception have been drafted onto bodies that pose a threat to the state. As othering accelerates, so do the regulations of the state and its frameworks which scramble to build more walls, document more about our lives, thicken the borders. It is particularly this confinement that made me interested in exploring the sites that agitate it. How do aspirations and dream making keep individuals, their sexuality, and their relationship with the state always in motion, and thus never static?

Hegemonic narratives around queer aspiring migrants translates their aspirations to a mere transition from point $A$ to point $B$ and renders invisible the spatial, affective, and subjective dimensions that are complicit in their movement. Some interpretations perceive the motives of queer aspiring migrants as the outcome of a

\footnotetext{
4 Dispositifs is defined by Foucault as "a thoroughly heterogenous ensemble consisting of discourses, institutions, architectural forms, regulatory decisions, laws, administrative measures, scientific statements, philosophical, moral and philanthropic propositions-in short, the said as much as the unsaid. Such are the elements of the apparatus. The apparatus itself is the system of relations that can be established between these elements" (Foucault \& Gordon, 1980, p. 194).
} 
desire for a move from the "dark East" to the "enlightened West," from an "oppressive" heteronormative state structure to a "liberal" homonationalist state ${ }^{5}$ (Puar, 2007). These narratives have been assimilated into political discourses to serve processes of international policymaking. It also fueled the othering of bodies, producing the image of the oppressed Arab homosexual other who, like the brown Afghani woman, needs to be saved from an "Islamist radical state."

In the U.S. for example, a country that figures in the migratory imaginations of Egyptian's Meem community, queer bodies have been incorporated within the state apparatus in a way that is conducive to nationalistic discourses about patriotism and the liberal rights bearing citizen (Puar, 2013; Richardson, 2017). This is an instance where the state has adapted its dispositifs of discipline in order to encapsulate sexualized bodies within constructs of national identity. The control and management of bodies guaranteed the security of the nation-state. Homonationalism has established itself as "a facet of modernity," which prompts us to question to what extent such narratives actually reiterated heteronormative discourses and adapted to neoliberal structures (Puar, 2013; Richardson, 2015).

The "subject" is fixed within the juridical apparatus through a narrative of rights and/or justice, which brings to the forefront questions regarding the position that the sexualized body seems to take in the frameworks of the state and within citizenship models. Justice and rights have come to be normalized as exclusive to the realm of the state and only attainable through law (Menon, 2004). What possibilities then can be attained if we push against "the institutionalization of rights?" What does the "subject" lose in the fixing of sexuality to the realm of the state?

Diane Richardson (2015) provides us with an interesting review on sexual citizenship literature in her article "Rethinking Sexual Citizenship," in which she explores how a large corpus of the literatures contributed to a rethinking of sexuality and citizenship. In an attempt to open up the potentialities and the ways in which we conceive of citizenship, sexual citizenship literature attempted to queer normalized framework of citizenship by dehomogenizing and rupturing its contours (Richardson, 2015). However, by adopting a language that is soaked in notions of rights and nation-state, sexual citizenship still navigated the same frameworks it attempted to escape, reincarnating the homogenous discourse of politicized existence. In "Wounded Attachments," Wendy Brown (1993) problematizes

...the ways in which certain troubling aspects of the specific genealogy of politicized identity are carried in its political demands, ways in which certain emancipatory aims of politicized identity are subverted not only by the constraints of the political discourses in which its operations transpire but by its own wounded attachment. (Brown, 1993, p. 391).

${ }^{5}$ Coined by Puar in Terrorist Assemblages (2007), the term "homonationalism" is defined as "a facet of modernity and a historical shift marked by the entrance of (some) homosexual bodies as worthy of protection by nation-states, a constitutive and fundamental reorientation of the relationship between the state, capitalism, and sexuality" (Puar, 2013). 
Sexual citizenship or citizenship in itself is a form of violence, which is echoed in the fixing of the subject to the sites of the state, limiting bodies to invest in processes of becoming (Menon, 2004). The limitation according to Richardson (2015) is more broadly attached to the notion of citizenship in itself that positions the state as the sole arbitrator of change and justice.

Richardson (2015) acknowledges the boldness that the literature on sexual citizenship had to offer in terms of deconstructing a lot of preconceived notions about sexuality, the state, and the politics of identity. However, she thinks that the literature still retained limitations and much of the western colonial legacies in regards to citizenship frameworks. She declared that "the conceptual framing of sexual citizenship border understandings in ways that are constitutive of processes of exclusion and cultural othering" (Richardson, 2015 , p. 8). Frameworks of sexual citizenship in a way reiterate a binary understanding of citizen vs. state, public vs. private, which normalizes the "production of new others" (Richardson, 2015). The underlying dimension of these master narratives inevitably limits potentialities for new ways of living (Braidotti, 2005). In a way, it is the deterministic elements that constitute the approaches to sexual citizenship that trouble Richardson (2015), whether in the academic discourse or outside of it. By decolonizing the concept of sexual citizenship, we can then broaden the scope of our exploration of the migratory aspiration of queer bodies, and not be primarily limited to the regulatory structures of the state. The contours of sexual citizenship are but an element within the vast intersections of subjectivities, power geometries, affective modalities, and subject making machinations.

\section{On the "Subject" in Becoming}

Subjectivity for Richardson (2015) is more complex than a Marxian social theory of "determinism," where the individual is inevitably tied to a set of internalized structures that determine how they act and how they are driven. Social theorist Anthony Giddens argued that the subject is "always at least partially 'knowing,' and thus able to act on and sometimes against the structures that made them" (Ortner, 2005. p.33). Processes of sociopolitical structuring within the various arenas of power - whether that is translated into forms of sexual citizenship or otherwise - do not enslave bodies in an endless production of regulated desires, movement, and aspirations (Ortner, 2005). Subjects, however, have "some degree of reflexivity about themselves and their desires," and are able to "penetrate" the modes of power and the apparatuses of control (Ortner, 2005, p. 34). Sherry B. Ortner (2005) defined subjectivity as "the ensemble of modes of perception, affect, thought, desire, fear, and so forth that animate acting subjects" (31). So even though Meem aspiring migrants in the workshop seemed to dream of a "better" life by aspiring towards "better" forms of citizenship, this essentialized interpretation of migratory aspirations completely ignores the different degrees of knowing that are incarnated in the subject and their capacities to act on them.

In unpacking migratory aspirations, a more nuanced understanding of subjectivity lends itself to us. Conversations surrounding migration that occurred in the workshop space were not a mere articulation of different structures of citizenship; rather, they were an act of coming together to exchange stories and personal aspirations, which reveals the capacity of the participants' personal subjectivities to play a role in 
their own movements, and in how to act on their hopes and dreams. This understanding does not attempt to ignore the formations that contribute to the "shaping of subjectivities within a world of wildly unequal power relations," but it recognizes that these formations are not linear or a one way street. Instead, "the complexities of personal subjectivities within such a world" articulates itself in a variety of ways in the everyday (Ortner, 2005, p. 46). As nearly everyone in the room raised their hand when the workshop facilitator asked who sought migration, one participant, whom I will call H.N., did not. She leaned over to me and said that she felt guilty, being one of very few participants who already had a ticket out of the country. She was an American citizen, and she had that green passport that everyone in the room seemed to covet. In a mix of Arabic and English, she told me, "Family is an integral part of my identity, and for me, it isn't easy to go about something like that." But there were so many different factors that affected her feelings towards migration. She still wanted to leave the country at one point with her girlfriend, but at the same time she had so many other reasons that made her consider and reconsider migrating: family, friends, financial situation, and personal desires and fears.

One thing that drives me is the idea of being more myself, being surrounded by people who do not see my relationship with someone else as a problem... and whenever I think about my wedding, I think of my parents being present, and that being one of the happiest moments of my life (H.N.).

\section{Mental Migration and Dream Making}

The imaginary capacities of the subject can be conceived as a form of mobility which lends more potentialities for subjectivities to restructure borders and shape experiences (Bal and Willems, 2014; Salazar, 2011). The mental migration of queer bodies becomes rather as revealing as the materialization of migratory aspirations. For movement does not have to be palpable to the mind's eye; we migrate in our head all the time, create other selves, other time-space. We think of the impossible, articulate it in words, in images, translate them and retranslate them. We are always resorting to different lingos to narrate/articulate our dreams. In a sense, then, border crossing entails a temporal investment in dream making, and mobility is fueled by the "ability of travelers and their networks to imagine other places and other lives" (Salazar, 2011, p. 577). "Even when a person is place-bound," their imagination is in motion, drawing on a conglomeration of images, desires, fears, and aspirations (Salazar, 2011, p. 577). There is always an "else-where," whether spatial, temporal, or dimensional, that captivates a person's aspirations, a phantasmal "there" that renders a person's body, their sexuality, and their relationship to the state always fluid.

What is it that constructs these imaginaries? One theory that Ellen Bal and Roos Willems (2014) find problematic is the push-pull framework, a classical theory that contends economic factors to be the primary drive for people's migration. This approach ignores the potentialities intrinsic to subjectivities - the personal and affective forces that are significant in forming migratory aspirations (Bal \& Willems, 2014). Noel Salazar (2011) provides a more comprehensive understanding of migratory imaginations in "The Power of Imagination in Transnational Mobilities," where she perceives them as "an embodied practice of 
transcending both physical and sociocultural distance" (Salazar, 2011, p. 577). Imagination is then socially constituted within the geopolitical space of the here and now. Circulating ideas of "other places" and other "good lives" shapes migratory aspiration. It is at times the act of collective imagination, set by the tones of stories and myth surrounding other homelands that underlie people's movements. So even if the material aspiratory migration of the Meem community within the workshop are not realized, they are still engaging in different forms of mental migration by creating images of the lives they desire, and the places and spaces they dream of inhabiting. This was particularly explicit in the discussions and conversations in the workshop where several people shared their desire to move from a "here" to a "somewhere else" - not really specifying where that was. The "somewhere else" is a product of the imagination that fuels and is fueled by the aspiring migrants' desires, hopes, and emotions, and becomes a facet that shapes their subjectivities.

\section{The Multiple Heads of Control}

To say that power took possession of life in the nineteenth century, or to say that power at least takes life under its care in the nineteenth century, is to say that it has, thanks to the play of technologies of discipline on the one hand and technologies of regulation on the other, succeeded in covering the whole surface that lies between the organic and the biological, between body and population. We are, then, in a power that has taken control of both the body and life or that has, if you like, taken control of life in general - with the body as one pole and the population as the other. (Foucault \& Ewald, 2003)

In breaking away from a dichotomous understanding of migratory aspirations, how then can we look at the dispositifs managing queer bodies without rendering invisible the affective subjectivities and practices of dream making that come to shape their mobility? I have found that Lazzarato's corpus lends a more nuanced understanding to migratory aspirations. He does not discuss migration directly in his work, but his approach accounts for the complex subjectivities of aspiring migrants and breaks away from a binary understanding of their practices. He moves away from deterministic understandings of the subject as solely driven by monetary constraints and a slave to the accumulative capacities of a market driven economy. Lazzarato's (2006) understanding of the modern structures of neoliberalism also complicates our understanding of expulsion. For the expulsion of bodies and their marginalization is not a sole consequence of the global structures of capital. Instead, "regimes of signs, machines of expression and collective assemblages of enunciation (law, knowledges, languages, public opinion, etc.)" play a significant role in the subjection of bodies (Lazzarato, 2006, p. 172). This is not to deny or dismiss the power that capital employs in the sorting of people, places, economies, and bits of life (e.g., the environment) (Sassen, 2014). However, Lazzarato's (2006) argument considers the intersection of various dispositifs of discipline, control and biopolitics in creating not a supranational structure, but a complex multilayered intersecting assemblage that modulates neoliberal bodies. In brief, Lazzarato's (2006) society of control is characterized by an assemblage of (1) technological dispositifs acting at a distance, or in other words, the affective power extended by the circulation of words, writings, images and symbols through technological means like the Internet, the telephone, the radio, etc.; (2) biopower that invests in the control of "overall 
processes that are specific to life—such as birth, death, production, and illness" (Lazzarato, 2006, p. 178);

and (3) the control of population through the manipulation "of collective perceptions and collective intelligence," which is extended through "the brain's power to affect and become affected" (Lazzarato, 2006 , p. 180). The society of control is then constructed by the disciplining of bodies through various modes of intervention and management, those being the capturing of bodies in disciplinary institutions (school, hospital, etc.), the administration of territories, and the control of knowledge circulation, signs, images, language and symbols (Lazzarato, 2006). The societies of control in a sense modulates the production of desires, knowledge, beliefs and aspirations. As Lazzarato contends:

The capture, control and regulation of the action at a distance of one mind on another takes place through the modulation of flows of desires and beliefs and through the forces (memory and attention) that make these flows circulate in the cooperation between brains. (Lazzarato, 2006, p. 185)

Exploring Lazzarato's account of the subjection of bodies however, does not mean that subjectivity is an absolute prisoner to the dispositifs that he identified. This was especially explicit in the workshop on migratory aspirations, where the participants discussed the different ways in which they can engage with or circumvent the structures of borders, visas, migration procedures, images, and technology in a concoction (tabkha), ${ }^{6}$ or in other words, the ways in which they can oscillate between these dispositifs in order to realize their aspirations and dreams. Several cases were shared amongst the participants of individuals from the Meem community who have fabricated court cases in which they claimed they were subjected to one form of oppression or another on account of their sexuality. The aspiring migrants presented these cases as proof of their threatened status in their home country, and as support for their political asylum applications. The coming together of Meem individuals does not mean then that as a collective, they occupy a homogeneous time/space framework, but each individual intersects and overlaps within the different layers and assemblages of the everyday to shape and reshape their individual positions within the society of control. It would be reductive in a way to tie the participant's dreams of migration to their sexuality alone. Instead, the multilayered intersecting forces constitute their migratory aspirations. This was clear in the expressions of the participant's diverse opinions regarding the most "suitable" countries to migrate to, which revealed intersections between sociocultural positionalities, race, sexuality, ethnicity, and religion, as well as a consideration of the economic opportunities that a specific country may lend to them. When the facilitator showed a slide that compared potential countries to immigrate to, participants shared opinions about the easiest languages to learn, anecdotal experience about the most discriminatory countries against immigrants, and suggestions on where they were most likely to secure a good education or job. When considering where to invest migratory aspirations, all these intersections and the complex ways that they structure themselves in the subject's everyday within the society of control come to play a significant role.

${ }^{6}$ An Arabic word that literally means dish or a concoction, which means a "mixture of various ingredients or elements" (Oxford Dictionaries). 
The creation of this particular workshop space where individuals from the Meem community can discuss their migratory aspirations, share stories and experiences, and invest in dream making reflects the potentialities that can be envisioned and practiced. The workshop space itself brings out the potential routes that can be navigated by queer bodies that aspire to migrate, and the ways in which their subjectivities engage in a continuous maneuvering of the society of control. The Meem community in the workshop navigated the everyday through strategies of "jumping scale;" they employed the elusive language of the state and reterritorialized borders. They also turned the mechanisms of the society of control and its inclusive/exclusive dimensionalities around itself to engage in processes of becoming and to claim their space.

Although the notion of "jumping scale" is used in spatiality literature to refer to the rescaling of territories and borders, I apply it in this context to refer to the continuous rescaling of aspirations and subsequently subjectivities of queer bodies. Falling "in" and "out" of legality, occupying a border in between the master narratives of homonationalism and Egypt's heteronormative state discourses, the purposeful assimilation into master narratives in order to reach personal goals, and the oscillation between the categories of migrant, asylum seeker, and professional immigrant are all examples of what jumping scale strategies can offer. Meem aspiring migrants in this context make use of the state sanctioned immigration system - its inclusive and exclusive features - to attain their dreams. Their mental or material migration is an investment in escape routes that widens the potentialities of their movement and the capacities of their imagination (Papadopoulos, Stephenson, \& Tsianos, 2008). I was once told that statistics strip human experiences of their complexity and nuance. I believe then that talking about mental migration reveals a different understanding of movement that cannot be traced on a map or compiled in a datasheet. 


\section{References}

Andrijasevic, R. (2009). "Sex on the Move. Gender, Subjectivity and Differential Inclusion." Subjectivity, 29(1), 389-406.

Agamben, G. (1998). Homo Sacer: Sovereign Power and Bare Life. (D. Heller-Roazen, Trans.) (1 edition). Stanford, Calif: Stanford University Press.

Agier, M. (2011). Managing the Undesirables: Refugee Camps and Humanitarian Government. (D. Fernbach, Trans.) (1 edition). Polity.

Bahgat. (2013, March 6). "Explaining Egypts Targeting of Gays." Retrieved April 16, 2017, from https://web.archive.org/web/20130306142709/http://www.merip.org/mero/mero072301

Bal, E., \& Willems, R. (2014). "Introduction: Aspiring migrants, local crises and the imagination of futures 'away from home'." Identities, 21(3), 249-258. https://doi.org/10.1080/1070289X.2014.858628

Brown, W. (1993). "Wounded Attachments." Political Theory, 21(3), 390-410. https://doi.org/10.1177/0090591793021003003

Foucault, M., \& Ewald, F. (2003). "Society Must Be Defended:" Lectures at the Collège de France, 19751976. Allen Lane.

Foucault, M., \& Gordon, C. (1980). Power/knowledge: selected interviews and other writings, 1972-1977. New York: Pantheon Books.

Human Rights Watch (Organization) (Ed.). (2004). In a time of torture: the assault on justice in Egypt's crackdown on homosexual conduct. New York: Human Rights Watch.

Lazzarato, M. (2006). "The Concepts of Life and the Living in the Societies of Control." ResearchGate, 171-190. https://doi.org/10.3366/edinburgh/9780748620920.003.0009

Luongo, M. (2012). "Egypt's fading LGBT movement." Retrieved June 27, 2017, from http://www.salon.com/2012/03/08/egypts_fading_lgbt_movement/

Ortner, S. B. (2005). "Subjectivity and cultural critique." Anthropological Theory, 5(1), 31-52. https://doi.org/10.1177/1463499605050867

Papadopoulos, D., Stephenson, N., \& Tsianos, V. (2008). Escape Routes: Control and Subversion in the Twenty-First Century. London; Ann Arbor, Ml: Pluto Press.

Pratt, N. (2007). "The Queen Boat case in Egypt: sexuality, national security and state sovereignty." Review of International Studies, 33(1), 129-144. https://doi.org/10.1017/S0260210507007346

Puar, J. (2007). Terrorist Assemblages: Homonationalism in Queer Times. Durham: Duke University Press Books.

---. (2013). "Rethinking Homonationalism." International Journal of Middle East Studies, 45(2), 336-339. https://doi.org/10.1017/S002074381300007X

Richardson, D. (2017). "Rethinking Sexual Citizenship." Sociology, 51(2), 208-224. https://doi.org/10.1177/0038038515609024

Salazar, N. B. (2011). "The Power of Imagination in Transnational Mobilities." Identities, 18(6), 576-598. https://doi.org/10.1080/1070289X.2011.672859

Sassen, S. (2014). Expulsions: Brutality and Complexity in the Global Economy (First edition). Cambridge, Massachusetts: Belknap Press: An Imprint of Harvard University Press. 
Kohl 3.1

104 Stack, L. (2016, August 10). "Gay and Transgender Egyptians, Harassed and Entrapped, Are Driven Underground." The New York Times. Retrieved from https://www.nytimes.com/2016/08/11/world/africa/gay-egyptians-surveilled-and-entrapped-aredriven-underground.html 